\title{
The Analysis of Mobile Games Profit Model
}

\author{
Yin Hang \\ Engineering Training Center \\ Shenyang Aerospace University \\ Shenyang, China
}

\author{
Liu Chang \\ School of Economic and Management \\ Shenyang Aerospace University \\ Shenyang, China \\ e-mail:896835136@qq.com
}

\begin{abstract}
Nowadays, mobile games have already become one of the indispensable entertainments in people's spare time, especially as smart phones gradually become popular, mobile Internet technology becomes mature, mobile game industry is in rapid development and the industry scale is also expanding. Therefore, the analysis for the profit modes of mobile games are also particularly important. Now from the point of smart phone operating system market, Android accounts for most of the global mobile operating system market shares, but in the field of enterprise users, iPhone and iPad of Apple are still dominant. The new concept of $\mathbf{4 G}$ network technology will also bring more developing possibilities for mobile game market. On the other hand, there are too many homogeneity products in the mobile games market and the infringement is serious. The copyright maintenance still needs improving.
\end{abstract}

Keywords- Mobile Games; Profit Modes; Innovation; Platform

\section{INTRODUCTION}

With the reducing of the mobile phone production costs and the upgrading of the hardware and software technology, more and more ordinary people begin to use smart phones. It can be said that, in modern society, almost everyone has his or her own mobile phone. And with the mature of mobile Internet technology, the function of mobile phones are no longer limited to calling and texting, users prefer to use mobile phones to chat on the Internet, watch video, play games and other activities.

China is increasing the construction of $4 \mathrm{G}$ networks. On the second conference of 12th National People's Congress, Mr. Li Keqiang, the premier of the state council, pointed out in Government Work Report that China has to speed up the development of $4 \mathrm{G}$ networks, implement the strategy of making broadband cover China which is to increase the network speed to a large degree. Governments are actively trying to increase the basic construction of information engineering, and the mobile game is one of the beneficiaries.

\section{THE ANALYSIS OF MOBILE GAMES USERS}

A. The number of mobile online users grows and the trend of the future is good

Report of China's Internet development state statistic, published by CNNIC, surveyed the mobile phone network games year by year. The report pointed out that by the end of 2010, under the influence of the network charge and speed of mobile phones, the permeability of mobile phone network games is still low. And since 2011, the development of mobile Internet created a certain market space for the development of mobile games.

Entering the year of 2012, with the popularity of smart phones and the development of mobile Internet, the scale of mobile phone network game users is growing rapidly, which injects new vitality for the network game industry. Until December of 2012, the utilization rate of mobile network games in the mobile Internet users is $33.2 \%$, which increased by $3.0 \%$ compared with the same period in 2011. The user scale grew by $29.8 \%$ compared to the end of last year. In spite of the slowing growth rate, the user scale still maintained a rapid growth.

In 2014, the popularity of the hardcore mobile game market still grows, even terminal game companies, such as Wanmei and Sdo are also striding ahead the hardcore mobile game. The cards, RPG (role playing games) and other hardcore games come to the stage. In the future, with the development of mobile network and the popularity of smart phones, moderate hardcore mobile games will become the mainstream.

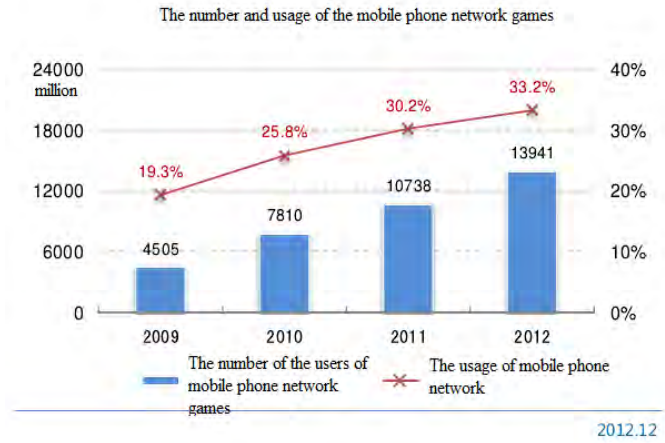
scale

Figure1. China mobile phone network game users

1) The game access is relatively fixed and the casual puzzle game is still the mainstream

The traditional method of downloading games through WAP websites is already a history. More and more players download mobile games through the app store directly. Statistics shows that over half of the intelligent mobile terminal users of China only focus on the top 25 game applications of game app stores, which shows the importance of mobile phone game platform.

Research indicates that, the most popular mobile games are casual puzzle games, which still has 
development space from the aspect of profit. The less popular mobile games are racing, Parkour and role playing games. However, card games were very popular last year, which still need reformation and innovation this year.

2) Low recognition of users to download charge modes

Data from iiMedia Research shows that $40.9 \%$ of users only accept free game mode, only $29.6 \%$ of them accept free mobile games with advertisements and $11.3 \%$ of them only accept the games without advertisements.

Being different from the European and American users who have high recognition in paying for games, the mobile uses of China have a low recognition to the games which are not free. Most of Chinese users prefer to download free games or pay for games after playing in advance. As a result, value-added mode, which is paying for the props in games is the current domestic mainstream for mobile game manufacturers to make profit.

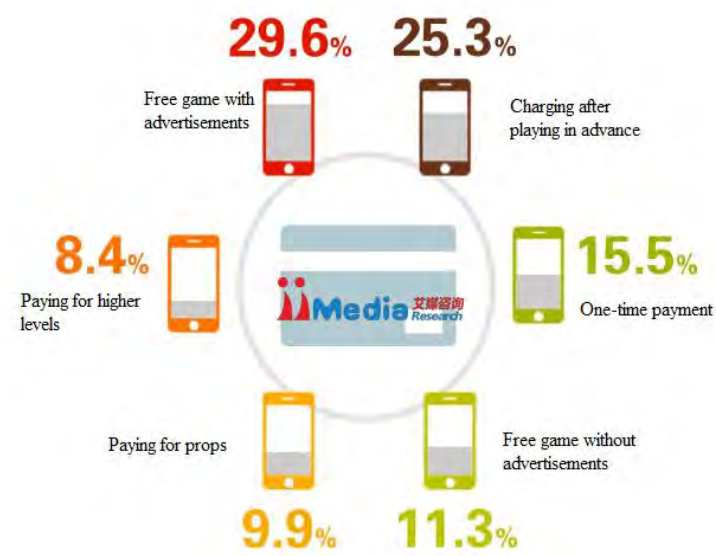

Figure2. Recognition situation of users to the charge modes of the mobile games of China in 2013-2014

\section{PROFIT MODES AND PAYMENT MODES OF MOBILE GAMES}

\section{A. Profit modes of mobile games}

\section{1) Download payment mode}

The model refers that users can have the permanent right or can unlock all levels of the mobile game after paying for it for one time. The games adopt this mode are generally the well done games with high quality and certain brand appeal.As is known to all, there are Pay List and Free List on App Store of Apple. The games on the Pay List are of this payment mode. The mode can get a quick income which has to be shared. The users who only accept free games would not like to pay for the charged games.

\section{2) Content payment mode}

Content charge mode is commonly used for those free high-quality games. For there is a lack of fame, some powerful game teams apply free mode. But there are only a few free levels in the game. If users want to continue playing the game, they have to pay to unlock the following levels. It is like the cake shop. We can taste the cake for free. If we like the cake, we have pay for it. The mobile games of casual puzzle class Cut Rope and Cut Rope II are free at the first few levels. If users want to enter the following levels, they have to pay 6 RMB to see the lovely frog.

\section{3) Value-added service mode}

It is the most mainly used mobile game profit mode. In this mode, mobile games can also be downloaded for free and even all the contents of the game is free to users. But if users want to have better game experience and pleasure, they have to pay. Although it is a free game, it can get more profit compared with the games of payment mode which can be said to be a one-time payment. No matter how good the game itself, users only have to pay for the game one-time to have the game permanently. In the payment mode, the income is relatively fixed. However, value-added model is different, although the game itself is free, but if users want to get better service or become high-end users, they have to pay for the game constantly.

4) Advertising mode

Advertising mode is used for the rough games, whose profit mainly depends on advertisement flow. When users run a game, there will be a scrolling advertisement bar. During the user is playing the game, the game developers can get profit of a few cents each time when the advertisement bar changes into another piece. On the uneven APP store, there are many games which apply this mode. And the game which apply this mode are mainly designed by junior rookie teams and the game developers who don't have strong independent ability.

\section{B. Payment modes of mobile games}

After talking about profit modes, the following point is to talk about payment modes which are the supplement to profit modes. At present the main payment modes of the mobile game users in smart phone games in China are as follows:

Prepaid phone card payment: Prepaid phone cards are mainly sold in Internet cafe, supermarket, newspaper office, etc. Users get the top-up account passwords and charge the the virtual currency into game accounts.

Online top-up: In recent years, with the rise of mobile payment, this mode spreads quickly. This payment mode is convenient and quick without the trouble to go out for charging. It can bring a better game experience for users.

Telecom binding payment: The mode refers that users generally use a mobile phone, a fixed phone or web services accounts as payment terminals. The payment will be completed by telecom operators' deducting the fees directly from users' accounts.

Message withholding payment: The mode refers that users complete the payment through the messages sent by elecom operators. This is the most widely used payment mode in intelligent mobile game market. Because of the stability of its payment channel, the 
payment mode is convenient and welcomed by the majority of users.

As in recent years, the emergence of mobile phone online banks, the opening of mobile payment and Wei Chat payment, more and more people begin to use mobile application terminals for payment directly. Although the payment becomes more convenient, the safety remains to be improved. It is believed that in near future, mobile payment platforms will become the mainstream of payment.

\section{The innovation and improvement of mobile game profit modes}

\section{The block of the mobile game market development} of China

1) The fake copy situation is serious and copyright maintenance is difficult

On the game market of China, there is a serious problem which is the fake products. From the terminal games, website games to mobile games, there are various kinds of fake products.

Short cycle, low cost and high return make a lot of teams would like to take the adventure. Because if the fake product is successful, the profit is more than the cost which is to pay for the copyright issues.

Too many advertisements make users' experience deduce. At present, the main income of most of the mobile games of China is still advertisements.

2) Network flow is less and the network speed is critical

2014 China's mobile network flow using report (first phase) which was issued by 360 mobile security center shows that in mobile Internet users of China, the mobile phone users who use $3 \mathrm{G}$ network become more and more while the $2 \mathrm{G}$ users become fewer and fewer significantly. The complain to the low network speed from the mobile phone users of China is much more than the complain to the few network flow.

3) The game itself has problems and the quality is uneven

Under the pressure of market competition and the characteristics of mobile game life cycle, game makers must constantly update to ensure the adhesion degrees of users. They have to solid the existing users while developing new users. As a result, the product development cycle has to be shortened which also causes the quality problems of games.

To meet the industry reshuffle, the stress of small and medium-sized enterprises are under great press. The popularity of mobile games in nearly two years attracted a large number of enterprises and mobile phone develop teams to join in, which rapidly increases the competition in the industry.

\section{IMPROVEMENT AND INNOVATION OF MOBILE GAME PROFIT MODES}

In 2014, as 4G network begins to promote, the smart phone operating system improves and the capital which various industry manufacturer enterprises invest to the mobile phone market increases, the market competition will become more fierce. In 2013, card games were boom, the emergence of a number of outstanding works, such as Million Athur, "I'm MT", etc. brought new vitality to mobile games and also received positive responses. On the other hand, the contents and rules of card games have become immobilized with no innovation. In this year, the card games have to innovate to maintain their vitality. Also, the profit modes of mobile games also needs innovation and improvement.

\section{A. The mobile game derivatives}

When a game becomes a success, the benefits brought by the game itself is limited. However, the value created by the game is far more than the game itself. The simplest example of this is the industrial chain around the game. The mobile phone gaming industry is no exception. A good mobile game can even establish its own brand. Being liked and recognized by users and users' willing to pay for the game can explain the success of the game. In this respect, Rovio is the first one which became hot globally by Angry Birds. After successfully launched the first stuffed toy, Rovio launched a series of peripheral products with highaltitude. The company even made film and park with the theme of Angry Birds.

Casual games are relatively easy to get high popularity in a short term, which also provides peripheral conditions for product development and sales. But now this mode is not widely used. The mature of mobile games and the improvement of game quality and brand in the future may make the derivatives profit mode become popular.

\section{B. Soft advertisements}

Happy Farm and Iconic gradually faded, because this mode has a high playability of games. As a result, the game mode doesn't adapt to the market. Recently, however, a 3D music and dance mobile game with the background of "the female god of indoorsman"Annri Okita, which is called Party Beauty adopted this mode. Because of the unique design and the charm of the spokesperson, the game attracted many users to join in. Now there are several dance companies and IT companies prepare to invest in this screen, from which we can see that the background is a highest grossing of the game. On the one hand, the background can be users' display area to meet their vanity psychology. What's more, the background also can undertake advertisements, which will not affect the users' experience, but obtain very high visibility.

\section{IP acquisition and innovation}

The quality, rules and channels of a game are very important to the development in the early period of mobile game industry, which can be seen from the classic games with good word of mouth and long influence. Now good IP starts to coruscate their own glorious. IP has become an important reference index evaluation of games. Because when games become more and more, the quality is getting better and better, the channel becomes more and more mature, spread and popularization cost also increase and the effect is no longer apparent.

But if the development of mobile game market wants to be on track, game companies want to develop 
wonderful games, they should not forget the basis of games that innovation is the real power. The acquisition of IP and getting profit is only a temporary. Returning to the game itself is the core.

\section{The platform cooperation and win-win benefit}

Recently, Alibaba has officially announced that it would launch autonomous mobile game platform. With the use of its resources across the platform, from the game distribution to the operating platform and sharing modes, Alibaba made full breakthrough and tried to change the current mobile game market mode that Tencent is dominating the world.

The President of Digital Entertainment Group of Alibaba, Liu Chunning, said that for stand-alone game partners, Alibaba would provide free service in the first year. They will adopt the sharing mode of $8: 2$ jointing operating games, in which the game developer will win $70 \%$ yield, while Alibaba is taking $20 \%$ which are cover costs and incentive, and the remaining $10 \%$ will be used to support the development of the education of rural children. The spokesperson of Alibaba Group, Wang Shuai said that if the game industry still took 1:9 sharing mode (in which the operation party takes $90 \%$ and the content developer takes $10 \%$ ), the deformity of game industry will not change and Wei Chat also won't escape the fate of the mode.

Regardless of the right or wrong between Alibaba and Tencent, at least, I don't think it is reasonable for some of the game platform companies currently to take the larger proportion.

360 Company adopted a strategy which means not to take portion from the platform online products whose income is less than 500,000 in 3 months. The strategy is to attract more small and medium-sized developers to take 360 platform as their product testing fields. On the other hand, it also helps 360 to find out high quality products and to win advantages in the issuing battle of this year.

\section{CONCLUSION}

The development of mobile games has been a history of more than a decade. The games can be divided into word games and graphics games. Word games can be mainly divided into two categories, which are SMS games and wap browser games. The graphics games can be divided into embedded games, java games, Brew games, Unit-java games, N-GAGE games, mrp domestic games. Windows mobile games, iPhone games, etc. (only including the categories which can be seen in our country).

At the beginning, Nokia phones had the built-in game "Snake", then JAVA games became popular later.
Again to now, there are intelligent mobile games which are applied to Android and IOS smart phone operating systems. Now, with the popularity of smart phones and the mature of mobile Internet technology, intelligent mobile games are developing and the mobile phone network games are moving forward step by step.

It can be believed that in the future, mobile games will be developed toward the direction of the advanced, 3D large-scale online games are no longer a proverb. The users' experience will be focused on in the first place. And with the development of mobile network and the decline of Internet rates, the mobile network games are the development mainstream, the profit modes of mobile games should be changed according to the market, which will be more in line with the trend of the time. The research aim of the paper is to provide ideas for the development of the game operators and developers, complement each other, avoid disadvantages and make mobile game market develop more stably and orderly.

\section{REFERENCES}

[1] Enfodesk. The market quarterly monitoring of China's smart phone games--- the first quarter of 2013[R/OL].http://www.enfodesk.com/d, 2014-05-05.

[2] Enfodesk. 2012 annual comprehensive report on Chinese smart phone game market[R/OL].http://www.enfodesk.com/, 201405-05.

[3] Iimedia. 2013-2014 China mobile game market annual report[R/OL].http://www.iimedia.com.cn/, 2014-05-05.

[4] Desheng, Kong, Lin, Bai. Mobile game industry analysis[J], Economic management, 2013(24):172

[5] Jihua, Ma. The mobile phone game industry of $3 \mathrm{G}$ era[J]. Information network, 2010(Z1):110-113

[6] Yueyun, Zhong, Liubo, Ouyang. The development bottleneck of $3 \mathrm{G}$ mobile games[J]. Fujian Computer,2010(9):40-41

[7] Tianxiang, Zhang. On the development prospect of China's mobile games[J]. Youth Journal, 2013(4):80

[8] Ying, Tuo, Hao, Shen. The analysis of mobile game development present situation and future trend $[\mathrm{J}]$. Gansu Science and Technology,,2013，29(5):79-80

[9] Weike, Liang, Evasion of the social negative effect behind mobile phone game industry prosperity[J]. Journal of Lanzhou, s2011(8):67-72

[10] Hyun Jung Park,Sang-Hoon Kim.A Bayesian network approach to examining key success factors of mobile games[J]. Journal of Business Research,2013,66(9):1353-1359

[11] Penttinen,Esko,Rossi,Matti,Tuunainen,VirpiKristiina.Mobile Games:Analyzing the Needs and Values of the Consumers[J].JITTA:Journal of Information Technology Theory and Application,2010,11(1):5-21

[12] Tao Zhou. Understanding the effect of flow on user adoption of mobile games[J]. Personal and Ubiquitous Computing,2013,17(4):741-748 